\title{
Determination of Polonium-210 in various foodstuffs after microwave digestion
}

\author{
I. Louw ${ }^{1}$, A. Faanhof ${ }^{2}$ and D. Kotze ${ }^{1}$ \\ ${ }^{1}$ South African Nuclear Energy Corporation, PO Box 582, 0001 Pretoria, South Africa \\ ${ }^{2}$ North-West University, Private Bag X2046, 2735 Mmabatho, South Africa
}

\begin{abstract}
Natural radioactivity is associated with the vast mineral resources in South Africa in such concentrations that the radionuclides from the natural uranium and thorium decay series are found to pose concern for public exposure to communities living around these areas. The radiological impact of all operations is monitored as part of the license obligations, imposed by the South African National Nuclear Regulator Act [1]. Two main pathways giving rise to significant exposures are of interest: (a) direct ingestion resulting from regular and continuous use of contaminated water for drinking purposes, and (b) regular consumption of fish and other food products harvested from and/or grown in contaminated areas. To measure the individual nuclides in foodstuffs at the required sensitivity level in order to evaluate the yearly dose due to an individual source at a screening level of $25 \mu \mathrm{Sv} / \mathrm{a}$, one is faced with a required lower limit of determination (LLD) of 0.1 to $0.5 \mathrm{~Bq} / \mathrm{kg}$ for certain foodstuffs. For some of the nuclides this LLD can only be obtained with radiochemical separation through acid destruction of dried foodstuffs followed by individual element separations. In this study the digestion of foodstuffs in an open-vessel microwave system followed by the determination of ${ }^{210} \mathrm{Po}$ through radiochemical separation by spontaneous deposition onto silver discs and subsequent measurement by $\alpha$-spectrometry, has been evaluated. The levels of ${ }^{210} \mathrm{Po}$ in a variety of foodstuffs were determined and the estimated dose for the adult age group, resulting from consumption was evaluated. The dose from ${ }^{210} \mathrm{Po}$ varied from 4 to $250 \mu \mathrm{Sv} / \mathrm{a}$ for the various foodstuffs, with the largest intake from fish (about $0.5 \mathrm{~Bq} /$ day). The assessment of natural radionuclides in foods allowed us to evaluate the items that present the highest risk to the population, and compare this to the limits established by the National Nuclear Regulator (NNR). Not much data of this kind is available in South Africa. However, one would need more accurate consumption/intake values to calculate the actual yearly dose and the potential radiological impact on the public.
\end{abstract}

\section{INTRODUCTION}

As is commonly known a large contribution to the radiation dose received by humans comes from natural occurring uranium series radionuclides accumulated in the body. ${ }^{210} \mathrm{Po}$ is included in the group of highly toxic radioisotopes and contributes a substantial portion of the radiation dose to humans. According to Clayton and Bradley [2] about $18 \%$ of the average internal dose of the population is due to ingestion of ${ }^{210} \mathrm{Po}$ and its precursor ${ }^{210} \mathrm{~Pb}$. Consumption of food is usually the most important route by which natural radionuclides can enter the human body and assessment of natural radionuclide levels in different foods and diets is therefore important to estimate the intake of these radionuclides by man. Since the early 1960s some comprehensive studies on the concentration of ${ }^{210} \mathrm{~Pb}$ and ${ }^{210} \mathrm{Po}$ in foodstuffs and the dose due to intake of these radionuclides through diets, have been carried out in various part of the world [3-14]. In contrast, not much data on dietary intake of ${ }^{210} \mathrm{Po}$ and ${ }^{210} \mathrm{~Pb}$ in South Africa are available, except for studies on the ${ }^{210}$ Po content in marine organisms $[15,16]$.

In a preliminary investigation of the potential radiological impact of foodstuffs grown in a catchment area influenced by mining and mineral reprocessing industries in South Africa [17], natural radionuclides (excluding ${ }^{210} \mathrm{Po}$ ) were determined in a number of foodstuffs collected from the area. The radionuclides were measured by non-destructive techniques such as Instrumental Neutron Activation Analyses (INAA) and low background gamma spectrometry. The estimated dose from ingestion of some of these foodstuffs was fairly high and consequently considerable press attention was given to 
the "radioactive poison found in food". From the public point of view, it is important to ensure the population that the contaminant level in a specific food does not exceed the permissible limits.

The aim of this work was to establish the radiochemical method for ${ }^{210} \mathrm{Po}$ analyses in foodstuffs after microwave digestion of samples. The levels of ${ }^{210} \mathrm{Po}$ in a variety of foodstuffs were determined and the estimated dose for the adult age group, resulting from consumption, was evaluated. The radiochemical measurement of ${ }^{210} \mathrm{Po}$ is important due to its high dose conversion factor and the inability of the non-destructive techniques to measure with the necessary sensitivity of 0.1 to $0.5 \mathrm{~Bq} / \mathrm{kg}$ (wet weight) required for dose calculation purposes [18]. Previous studies [19] showed that using low energy gamma spectrometry, the values for ${ }^{210} \mathrm{~Pb}$ (and the assumed equilibrium with ${ }^{210} \mathrm{Po}$ ) are often overestimated due to the high detection limit for ${ }^{210} \mathrm{~Pb}$.

\section{MATERIALS AND METHODS}

\subsection{Food samples}

A variety of food samples from the six categories as defined by the World Health Organization [20] i.e. cereals and grains, meat, seafood/fish, vegetables, roots and tubers, and fruit, were analyzed. Most samples were collected in the vicinity of areas known to be influenced by mining and mineral processing industries. Samples were prepared as would apply for human consumption. Vegetables samples were washed to remove any adhering soil. Root crops were washed and peeled. In fish and beef the edible portions were separated from the bone prior to drying. The clean edible parts were taken and dried at $100-110^{\circ} \mathrm{C}$ to constant weight, milled and homogenized prior to analysis.

\subsection{Analytical procedure}

All analytical methods are validated and documented in the Quality System of the Radioanalytical laboratories of the South African Nuclear Energy Corporation, which is based on ISO/IEC Standard 17025. The laboratory is accredited with the South African National Accreditation Systems (SANAS).

\subsubsection{Sample dissolution}

Samples were dissolved using an open vessel microwave digestion system (Milestone Ethos Touch). Approximately $1 \mathrm{~g}$ of sample was digested for 20 minutes at $100{ }^{\circ} \mathrm{C}$ with concentrated nitric acid and hydrogen peroxide. Nitric acid was added periodically during digestion with peroxide being added in the final stages to obtain total dissolution. ${ }^{209}$ Po was added as yield tracer in the initial stages of the dissolution.

\subsubsection{Polonium-210 analysis}

After sample dissolution, the samples were filtered through a Whatman-541 filter paper. Nitric acid was removed by evaporating the solution and adding concentrated hydrochloric acid. The solution was diluted to a concentration of $0.5 \mathrm{M}$ hydrochloric acid and hydroxyl ammonium chloride was added. A silver disc was added to allow the spontaneous deposition of Polonium. The alpha activities of ${ }^{209} \mathrm{Po}$ and ${ }^{210} \mathrm{Po}$ were then measured with $\alpha$-spectrometry. The detection limit obtained for ${ }^{210} \mathrm{Po}$ for a $24 \mathrm{~h}$ counting time and chemical recovery of $70 \%$ was better than $0.3 \mathrm{~Bq} / \mathrm{kg}$ (dry weight) using $1 \mathrm{~g}$ of sample.

\section{RESULTS AND DISCUSSION}

\subsection{Sample dissolution}

The main problems with the analytical method could occur in the sample dissolution step. Dietary samples are usually decomposed by wet ashing with concentrated nitric acid. Drops of $\mathrm{H}_{2} \mathrm{O}_{2}$ are 
added for complete destruction of organic matter [21]. When organic material remains in the digested sample, charring occurs during the evaporation of the $\mathrm{HNO}_{3}$, which gives variable recoveries [22, 23]. Conventional digestion on a hot plate is slow and requires close attention to avoid the risk of crosscontamination, formation of insoluble salts, exposure to acid fumes and corrosion and charring during evaporation. Closed vessel microwave digestion offers complete and fast digestion without losses and uses small volumes of reagents, but sample size is limited to $0.5 \mathrm{~g}$. When wet digestion is carried out making use of microwave heating in open vessels, conditions are controlled so that many of the abovementioned problems are prevented.

Samples digested on a hot-plate were compared to samples digested with the microwave. In samples digested with $\mathrm{HNO}_{3} / \mathrm{H}_{2} \mathrm{O}_{2}$ on a hot plate for 4-6 hours at a low temperature organic residues persisted even though wet ashing appeared to be complete. Using the microwave with a combination of $\mathrm{HNO}_{3}$ and $\mathrm{H}_{2} \mathrm{O}_{2}$, the latter being slowly added during the second phase of the digestion, a clear solution with little undissolved material was obtained.

A series of food test samples spiked with approximately $100 \mathrm{~Bq} / \mathrm{kg}^{210} \mathrm{Po}$, were analysed. The results were within the acceptable range of $100 \pm 20 \mathrm{~Bq} / \mathrm{kg}$ and a mean radiochemical recovery of $66 \pm 17 \%$ was obtained. The good chemical recoveries and spectral quality indicate that matrix effects do not interfere in the experimental procedure and that foodstuffs can be successfully digested with nitric acid and hydrogen peroxide using open-vessel microwave digestion.

\subsection{Polonium-210 activity in food samples}

Analytical results for the ${ }^{210} \mathrm{Po}$ activity of a number of dietary samples are presented in table 1. As can be seen from the results the ${ }^{210} \mathrm{Po}$ content varied widely in different foodstuffs and also in foodstuffs obtained from different sources. To all these variations should be added the human factor: (a) consumption of foods vary widely in both quantity and composition between individuals, communities and countries, and (b) food preparation habits may influence the radionuclide content. Therefore, dose estimates may vary significantly from those based on assumed consumption rates.

The activity concentration of ${ }^{210} \mathrm{Po}$ in fish varied depending on the origin, with the highest values in the samples taken near the gypsum outlet of one of the mining and mineral processing plants. The high and dominant ${ }^{210} \mathrm{Po}$ concentrations in fish are to be expected, since ${ }^{210} \mathrm{Po}$ is known to accumulate in fish and seafood. The estimated intake of ${ }^{210} \mathrm{Po}$ from fish was $0.5 \mathrm{~Bq} / \mathrm{d}$.

The activity concentrations of ${ }^{210} \mathrm{Po}$ in beef obtained from different sampling sites, were similar. The concentration in chicken was quite high. Concentrations in the liver and kidney samples were very high, which can be expected since internal organs are known to accumulate ${ }^{210}$ Po. Concentrations of ${ }^{210} \mathrm{Po}$ in milk and mushrooms were quite low. Results for vegetable crops were not consistent. In general, the ${ }^{210} \mathrm{Po}$ activity was low $(<0.5 \mathrm{~Bq} / \mathrm{kg})$ for most of the vegetables, but differed between sites. The spinach and carrot samples from Site $C$ had very high ${ }^{210} \mathrm{Po}$ activity. The ${ }^{210} \mathrm{Po}$ concentrations in the "background" samples were not significantly lower than those in vegetables from other sites.

Studies under controlled conditions [24] have indicated that direct deposition from the atmosphere is the dominant process affecting activity concentration of ${ }^{210} \mathrm{Po}$ in the edible parts of leafy crops, whereas root uptake and translocation of intercepted activity to other plant parts is not an important process. Concentration of radionuclides in the above-ground parts of the plants, are therefore expected to be higher than in the roots. This was not found as a definite trend in the samples analyzed in this study. Although the concentration in beetroot was lower than in spinach, carrots had a higher concentration. In general spinach showed higher ${ }^{210}$ Po activity than cabbage, which suggests dominance of leaf deposition of ${ }^{210}$ Po from the atmosphere. Spinach requires minimal preparation prior to cooking, whereas the outer leaves of cabbage are usually removed, resulting in lower concentrations. The activity concentration of ${ }^{210} \mathrm{Po}$ in green vegetables may vary seasonally, and the values in different years could also be variable. Meaningful estimates of dose would require continual sampling of crops throughout the year. 
Table 1. Sample activity of ${ }^{210} \mathrm{Po}$ in $\mathrm{Bq} / \mathrm{kg}$ wet weight and Committed Effective dose for adult age group ( $\left.\mu \mathrm{Sv} / \mathrm{a}\right)$.

\begin{tabular}{|c|c|c|c|c|}
\hline Category & Sampling Site & ${ }^{210} \mathrm{Po}(\mathrm{Bq} / \mathrm{kg})$ & $\begin{array}{c}\text { Consumption } \\
(\mathrm{kg} / \mathrm{a})\end{array}$ & $\begin{array}{c}\text { Dose due to }{ }^{210} \mathrm{Po} \\
\text { intake }(\mu \mathrm{Sv} / \mathrm{a})\end{array}$ \\
\hline $\begin{array}{l}\text { Grains/Cereals } \\
\text { Maize }\end{array}$ & Backoround & $0.281+0.141$ & 150 & 50 \\
\hline Maize & Consumer & $0.531 \pm 0.211$ & 150 & 95 \\
\hline Oats & Site A & $1.39 \pm 0.339$ & 150 & 250 \\
\hline Oats & Site B & $5.64 \pm 0.36$ & 150 & 1015 \\
\hline Rye & Site B & $9.55 \pm 0.93$ & 150 & 1719 \\
\hline Lucerne & Site C & $0.498 \pm 0.083$ & 150 & 90 \\
\hline Vegetables & & & & \\
\hline Cabbage & Site B & $0.054 \pm 0.020$ & 55 & 4 \\
\hline Spinach [2] & Site B & $0.435-0.648$ & 55 & $29-43$ \\
\hline Spinach & Site C & $1.96 \pm 0.16$ & 55 & 130 \\
\hline Barley & Background & $0.375 \pm 0.110$ & 55 & 25 \\
\hline Asparagus & Site A & $0.213 \pm 0.084$ & 55 & 14 \\
\hline Roots and Tubers & & & & \\
\hline Spring Onion & Site A & $0.600 \pm 0.101$ & 55 & 40 \\
\hline Turnip & Site B & $<0.14$ & 170 & 15 \\
\hline Beetroot [2] & Site B & $0.255-0.281$ & 170 & $52-57$ \\
\hline Carrot & Site C & $2.78 \pm 0.31$ & 170 & 566 \\
\hline Fruit & & & & \\
\hline Lemon & Site C & $0.136 \pm 0.038$ & 75 & 12 \\
\hline Mushrooms & Consumer & $0.010 \pm 0.005$ & 55 & 1.6 \\
\hline Fish & & & & \\
\hline Marine [4] & Background & $1.15-3.17$ & 25 & $34-95$ \\
\hline Marine [5] & Gypsum outlet & $2.21-8.08$ & 25 & $66-242$ \\
\hline Fresh [4] & Phosphate mines & $0.627-1.65$ & 25 & $19-50$ \\
\hline Fresh [3] & Site D & $0.431-0.775$ & 25 & $13-23$ \\
\hline Meat & & & & \\
\hline Chicken & Site D & $1.63 \pm 0.314$ & 75 & 147 \\
\hline Beef [6] & Sites B, D, E & $0.115-0.250$ & 100 & $14-30$ \\
\hline Liver & Site D & $13.1 \pm 0.75$ & 100 & 1568 \\
\hline Liver & Site E & $6.93 \pm 0.516$ & 100 & 831 \\
\hline Liver [2] & RA Waste site & $0.532 \pm 0.639$ & 100 & $64-76$ \\
\hline Kidney [2] & RA Waste site & $3.04 \pm 13.2$ & 100 & $365-1582$ \\
\hline Milk & Site B & $0.162 \pm 0.075$ & 350 & 68 \\
\hline
\end{tabular}

Note: Number of samples in brackets; Sampling sites A-E refer to gold mining areas.

Another aspect to be taken into consideration is that studies on the radionuclide concentrations in the water of the wetland system [25] used to irrigate the crops only shows uranium to be the dominant radioactive component with ${ }^{210} \mathrm{~Pb}-{ }^{210} \mathrm{Po}$ only a fraction of that $(<1 \%)$. This together with the not really significant difference in ${ }^{210} \mathrm{Po}$ concentrations observed in background samples, i.e. not irrigated by the specific surface water source, may also indicate that the majority of ${ }^{210} \mathrm{Po}$ uptake is due to the radon concentration in the air generated from emanation of the uranium rich deposits in the area concerned, and not from the irrigation process as such.

The very high ${ }^{210}$ Po concentrations found in oats and rye samples from Site B is a cause of concern. The high results may be partly due to adhesion of soil particles to the leaves. For some above ground crops such as cereals, the edible portion is protected by inedible plant parts and the activity concentration in the edible parts will not be affected by direct deposition; this can explain the low activity values found for maize, relative to that of oats and rye. 
There is a wide variation in published concentration data. In general, the concentration of ${ }^{210} \mathrm{Po}$ for vegetables, fish, beef, milk and maize was in the overall range of values for other countries as reported in the literature [6-10], although activities for vegetables, especially root vegetables, were higher than literature values. The concentrations obtained in the background marine fish compared well with the global concentration of $2.4 \mathrm{~Bq} / \mathrm{kg}$ for fish [21]. High ${ }^{210} \mathrm{Po}$ content of $2.3 \mathrm{~Bq} / \mathrm{kg}$ was also found in wheat in other countries [6]. Individual samples with high activity concentration (chicken, carrot, oats and rye) should be considered as special cases and the reason for the high values further investigated.

\subsection{Committed effective dose}

Intake via ingestion depends on the dietary habits of the affected groups and/or individuals (which is also age related), and the concentration of the radionuclides concerned. The annual intake was estimated by multiplying the ${ }^{210}$ Po level present in the individual food by the amount of food consumed per year. Doses were evaluated using the dose conversion factor for ingestion exposure for ${ }^{210} \mathrm{Po}(\mathrm{Sv} / \mathrm{Bq})$, recommended by the ICRP [26]. The estimated yearly dose for adults from ${ }^{210}$ Po is reported in table 1. In the absence of data specific to South African conditions, default consumption values for foodstuffs as applied by the South African National Nuclear Regulator (NNR) were used [27]. It must be emphasized, however that these consumption values are not intended to be interpreted as an "average annual South African dietary intake", but are conservative values for use in screening assessments that will ensure that all critical groups are covered, and apply to broad categories of food. Although the consumption values were derived from reported values taken from the literature, they may vary. More accurate statistical information on real consumption rates is necessary to improve dose estimates.

For the specific marine fish source(s), the dose due to consumption of ${ }^{210}$ Po varied between 13 and $240 \mu \mathrm{Sv}$ per annum, with ${ }^{210} \mathrm{Po}$ expected to be the main contributor to the total dose. Freshwater fish are not consumed in large quantities by the average South African population, and the consumption rate of $25 \mathrm{~kg} / \mathrm{a}$ probably results in an overestimation of the calculated dose.

The high doses from liver and kidney arise from the unrealistic high consumption rate of $100 \mathrm{~kg}$ per annum used in the dose assessment. As expected the dose due to ${ }^{210}$ Po was smaller for vegetables than for fish.

Consumption of oats and rye from Site B will result in doses of higher than $1 \mathrm{mSv} / \mathrm{a}$ due to intake of ${ }^{210} \mathrm{Po}$ only, and doses may be as high as $20 \mathrm{mSv} / \mathrm{a}$ if all nuclides are considered. However, it is debatable whether they will be used as such for human consumption. It is more likely that they will be used as fodder and accordingly the pathways to milk and meat would be a better option to evaluate the dose to humans. As mentioned earlier, it is important to note that one can not make decisions based on the analysis of one sample of a specific foodstuff. These particular samples were taken in the dry season and it is most likely that the results may differ substantially if sampled in the wet season when irrigation requirements are reduced. Food processing can also greatly reduce the radioactive content of final edible products; neglecting the losses during food processing can lead to an overestimation of the calculated dose.

Assessment of dose from the natural radionuclides can not be justified by concentrating on ${ }^{210} \mathrm{Po}$, although ${ }^{210} \mathrm{Po}$ does make an important contribution. For example assumed equilibrium between ${ }^{210} \mathrm{Po}$ and ${ }^{210} \mathrm{~Pb}$ will result in an underestimation of the dose for those foodstuffs with $\mathrm{Po}: \mathrm{Pb}$ ratios much lower than 1. Equilibrium can only be assumed if the chosen vegetable is going to be stored for one or more years (e.g. canned foods). However, if the radionuclides are not measured with the necessary sensitivity, the dose will most likely be overestimated. Besides ${ }^{210} \mathrm{Po}$, natural radionuclides such as uranium $\left({ }^{238} \mathrm{U}\right.$, $\left.{ }^{235} \mathrm{U}\right)$; thorium $\left({ }^{232} \mathrm{Th},{ }^{228} \mathrm{Th}\right)$, radium $\left({ }^{228} \mathrm{Ra}\right.$ and $\left.{ }^{226} \mathrm{Ra}\right)$, were measured for most of the samples to assess the overall dose to humans via the consumption pathway. Non-destructive techniques such as INAA and gamma spectrometry were used for the analyses. Results are presented elsewhere [28].

If oats and rye are considered as fodder rather than human food, and liver and kidney samples are excluded because of the unrealistic high consumption rate of $100 \mathrm{~kg}$, the annual effective dose from 
${ }^{210} \mathrm{Po}$ varies between 4 and $250 \mu \mathrm{Sv} / \mathrm{a}$. For comparative purposes the average annual effective dose from ingestion of ${ }^{210} \mathrm{Po}$ in $\mu \mathrm{Sv} / \mathrm{a}$ is estimated as 12 in the UK diet [9], 128 in India [10], 54 in Poland [11], 8.7-22.6 in Brazil [8], 25-120 in Portugal [7] and 416 in Syria [6]. Greater than average doses up to $3.4 \mathrm{mSv} / \mathrm{a}$ are experienced by populations with diets high in seafood [10]. According to UNSCEAR [29] the average dose rate from ${ }^{210} \mathrm{Po}$ intake from food is $\sim 120 \mu \mathrm{Sv} / \mathrm{a}$.

\subsection{Evaluation of results}

The NNR Guide LG-1032 [27] refers to an annual screening assessment criterion of $25 \mu \mathrm{Sv}$ for a specific pathway, taking into consideration also the contribution from other pathways, so that an overall criterion of $250 \mu \mathrm{Sv}$ is followed. From the evaluation provided in table 1 , it can be seen that in many cases the calculated doses for adults exceed the screening criteria of $25 \mu \mathrm{Sv}$, as well as the overall criteria of $250 \mu \mathrm{Sv}$ due to a specific source. If all nuclides are considered the maximum exposure level of members of the public set at $1 \mathrm{mSv} / \mathrm{a}$, will probably be exceeded. This is of obvious concern and further investigation is mandatory.

Most of the foodstuffs analyzed in this study were collected from fields in the vicinity of areas influenced by mining and mineral industries. Although this results will give one a fairly good idea of what the impact of the activities are on local produce, it is not possible to use this data to give an estimate of overall dose from total diet. These samples are not the final product as used by the average consumer and the dose is probably overestimated since activity concentrations may be reduced through food processing.

\section{CONCLUSIONS}

The analytical method proved to be an appropriate methodology for determining ${ }^{210}$ Po in foodstuffs at low concentrations. The levels of ${ }^{210} \mathrm{Po}$ in food clearly indicate that the ingestion of food is an important route for acquisition of body-burdens of the nuclide. In general ${ }^{210} \mathrm{Po}$ is lower in meat, milk and vegetables than in cereals, and higher in fish and liver. From this study, it seems that public exposure could accumulate up to a few $\mathrm{mSv}$ per year, if these food sources are part of the food sources available to the communities living in and around the specific area. To calculate the actual yearly dose and potential radiological impact on the public much work remains to be done. The following needs to be considered: (a) Analysis of food purchased from local markets and retailers, (b) Determination of more accurate consumption/intake values and (c) Improvement of the LLD.

\section{Acknowledgments}

The authors thank the personnel from the RadioAnalysis Laboratory at NECSA for their invaluable assistance and dedicated work in performing the measurements.

\section{References}

[1] National Nuclear Regulator Act, "Act no 47 on Safety Standards and Regulatory Practise", South African Government Gazette, Vol. 414 no 20760, 1999.

[2] Clayton, R.F. and Bradley, F.J., Sci. Total Environ. 173/174 (1995) 23-28.

[3] Beasly, T.M. and Palmer, H.E. Nature 187 (1960) 211-212.

[4] Khandekar, R.N., Health Phys. 33:2 (1977) 148-150.

[5] Avadhani, D.N., Mahesh, H.M., Karunakara, N., Narayana, Y., Somashekarappa, H.M. and Siddappa, K. Health Phys. 81:4 (2001) 438-445.

[6] Al-Masri, M.S. and Al-Bich, F., J. Radioanal. Nucl. Chem. $251: 3$ (2002) 431-435.

[7] Carvalho, F.P., Health Phys. 69:4 (1995) 469-480. 
[8] Cunha, I.L., Bueno, L., Favaro, D.I.T., Maihara, V.A. and Cozzollono, S., J. Radioanal. Nucl. Chem. 247:2 (2001) 447-450.

[9] Smith-Briggs, J.L., Bradley, E.J. and Potter, M.D., Sci. Total Environ. 54 (1986) 127-133.

[10] Kannan, V., Iyengar, M.A.R. and Ramesh, R., Appl. Radiation \& Isotopes 54 (2001) 663-674.

[11] Pietrzak-Flik, Z., Chrzanowski, E.and Dembinska, S., Sci. Total Environ. 203 (1997) 157-165.

[12] Izak-Biran, T., Schlesinger, T., Weingarten, R. and Even, O., Health Phys. 56:3 (1989) 315-319.

[13] Skwarzec, B. and Jakusi, A., J. Environ. Monit. 5:5 (2003) 791-794.

[14] Yamamoto, M., Abe, T., Kuwabara, J., Komura, K., Ueno, K. and Takizawa, Y., J. Radioanal. Nucl. Chem. Articles 178:1 (1994) 81-90.

[15] Cherry, R.D., Heyraud, M. and Rindfuss, R., J. Environ. Radioactivity 24 (1994) 273-291.

[16] Heyraud, M., Cherry, R.D., Oschadleus, H.D., Augustyn, C.J., Cherry, M.I. and Sealy, J.C., J. Environ. Radioactivity 24 (1994) 253-272.

[17] Faanhof, A., Kotze, D. and Louw, I., "A first order assessment of the potential radiological impact of foodstuffs grown in a catchment area influenced by mining and mineral processing industries, using Instrumental Neutron Activation Analysis (INAA) and gamma-spectrometry", The $5^{\text {th }}$ African Conference on research reactor utilization, 2-3 December 2007, Cairo, Egypt.

[18] Faanhof, A., Czech. J. Phys., 50:2 (2000) 281-288.

[19] Faanhof, A. and Louw, I., J. Radioanal. Nucl. Chem. 249:1 (2001) 227-232.

[20] World Health Organization (WHO), "World Health Organization Derived intervention levels for radionuclides in food", Geneva, 1988.

[21] Saito, R.T. and Cunha, I.I.L., J. Radioanal. Nucl. Chem. 220:1 (1997) 117-119.

[22] Holtzman, R.B., J. Radioanal. Nucl. Chem. Articles 115 (1987) 59-70.

[23] Towler, P.H. and Smith, J.D., Anal. Chim. Acta 292 (1994) 209-212.

[24] Ham, G.L., Ewers, L.T. and Clayton, R.F., J. Radioanal. Nucl. Chem. 226 (1997) 61-65.

[25] Institute for Water Quality Studies (DWAF), "Report on the Radioactivity Monitoring Programme in the Mooi River (Wonderfonteinspruit) Catchment Area", Pretoria, 1999

[26] International Commission on Radiological Protection (ICRP), "Age-dependent Doses from Intake of Radionuclides", ICRP Publication 72, Oxford Pergamon, 1996.

[27] The South African National Nuclear Regulator, "Guideline on the Assessment of Radiation Hazards to Members of the public from Mining and Mineral Processing Facilities", LG-1032, Rev 0, 1997.

[28] Louw, I. and Faanhof, A., In preparation.

[29] United Nations Scientific Committee on the Effects of Atomic Radiation (UNSCEAR), "Sources and effects of ionizing radiation", Report to the General Assembly with Annexes, United Nations, New York, 2000. 
